CLINICAL STUDY

\title{
Glucocorticoid replacement therapy and vertebral fractures in hypopituitary adult males with GH deficiency
}

\author{
G Mazziotti, T Porcelli, A Bianchi ${ }^{1}$, V Cimino ${ }^{1}$, I Patelli, C Mejia, A Fusco ${ }^{1}$, A Giampietro ${ }^{1}$, L De Marinis ${ }^{1}$ \\ and A Giustina \\ Department of Medical and Surgical Sciences, c/o Endocrinology Service, Montichiari Hospital, University of Brescia, Via Ciotti 154, 25018 Montichiari, \\ Italy and ${ }^{1}$ Pituitary Unit, Department of Endocrinology, Catholic University of the Sacred Heart, O0168 Rome, Italy
}

(Correspondence should be addressed to A Giustina; Email: a.giustina@libero.it)

\begin{abstract}
Objective: GH deficiency (GHD) and glucocorticoid excess are associated with increased risk of fragility fractures. We aimed to evaluate whether the prevalence of vertebral fractures may be influenced by glucocorticoid over-replacement in hypopituitary males with GHD.

Design: Cross-sectional study.

Methods: Fifty-one adult hypopituitary patients (all males; mean age 55 years, range: 23-81) with severe adult-onset GHD (replaced in 21 patients and untreated in 30 patients) and glucocorticoid deficiency on replacement treatment were studied for vertebral fractures using a radiological and morphometric approach.

Results: Vertebral fractures were observed in 31 patients $(60.8 \%)$ in correlation with untreated GHD, urinary cortisol values, and cortisone doses. Patients were stratified according to treatment of GHD, and current and cumulative cortisone doses. In untreated GHD, vertebral fractures occurred more frequently in patients who had received higher (greater than median) cumulative and current doses of cortisone compared with patients who had received lower (less than median) drug doses (95.2 vs $50.0 \%, P=0.009$ and 90.5 vs $55.6 \%, P=0.04$ respectively). In untreated GHD, fractured patients had significantly higher urinary cortisol values compared with patients without vertebral fractures ( $84 \mu \mathrm{g} / 24 \mathrm{~h}$, range: $24-135$ vs $49 \mu \mathrm{g} / 24 \mathrm{~h}$, range: 30-96; $P=0.04$ ). In treated GHD patients, by contrast, the prevalence of vertebral fractures was not influenced by cumulative and current cortisone doses and urinary cortisol values.

Conclusions: Glucocorticoid over-replacement may increase the prevalence of vertebral fractures in patients with untreated GHD. However, treatment of GHD seems to protect the skeleton from the deleterious effects of glucocorticoid overtreatment in hypopituitary patients.
\end{abstract}

European Journal of Endocrinology 163 15-20

\section{Introduction}

Glucocorticoids are known to have potentially negative effects on bone metabolism, and glucocorticoid-induced osteoporosis is the most common form of secondary osteoporosis (1). The central mechanism of glucocorticoid action on the skeleton is the inhibition of osteoblast differentiation and function (2). It is clinically relevant that bone metabolism may be altered in terms of decreased bone turnover even in patients receiving glucocorticoids at standard replacement doses for adrenal deficiency, specifically when high doses are used (3). However, the effects of glucocorticoid overreplacement therapy on bone mineral density (BMD) seemed to be variable, and only data on clinical fractures are available (4-7).

GH and insulin-like growth factor 1 (IGF1) are anabolic hormones for bone with stimulating effects on bone modeling and remodeling, and with positive effects on longitudinal growth (8). Their main effect is stimulation of osteoblastogenesis and differentiated function of mature osteoblasts $(9,10)$. GH deficiency (GHD) in adult patients causes marked decrease of bone turnover with reduction of bone mass and increased risk of fragility fractures (11).

Most adult GHD patients have other pituitary deficiencies, such as gonadotropin, corticotropin, and thyrotropin deficiencies, the effects of which on bone metabolism and fractures of hypopituitary patients have not been completely clarified $(8,12-16)$. Moreover, it is unknown whether replacement therapies of other pituitary deficiencies may influence the skeletal abnormalities occurring in GHD, although an impact on quality of life and metabolic disorders was demonstrated (17-20). It is worth noting that hormones used to replace hypopituitarism (i.e. thyroxine $\left(\mathrm{T}_{4}\right)$, 
sex hormones, and glucocorticoids) may have direct effects on bone which may be clinically relevant in patients receiving relatively high doses of these drugs. Indeed, an overtreatment of hypopituitarism may occur in some patients, since replacement therapies do not completely mirror the endogenous hormonal production and their monitoring is also made difficult by the lack of good biomarkers of their action (20).

In a cross-sectional study, we have previously shown that untreated GHD was associated with high risk of vertebral fractures partially reverted by $\mathrm{GH}$ replacement (15). Since GHD causes skeletal abnormalities similar to glucocorticoid excess and glucocorticoid overreplacement was shown to produce negative skeletal effects more frequently in males than in females (4), we aimed at investigating whether glucocorticoid replacement therapy may influence the prevalence of fragility vertebral fractures in the subgroup of male patients with GHD, in relation to age, BMD, recombinant $\mathrm{GH}$ $(\mathrm{rGH})$ treatment, and other pituitary deficiencies.

\section{Materials and methods}

We evaluated with a post-hoc analysis 51 adult hypopituitary patients (all males, mean age 55 years, range: 23-81) as a subgroup of patients with severe adult-onset GHD enrolled in a previously published study (15) (Table 1). Forty-seven patients became GH deficient after surgical intervention for non-functioning pituitary adenomas, whereas GHD was secondary to empty sella in four patients. At the beginning of the study, 21 patients were on replacement therapy with $\mathrm{rGH}$, whereas 30 patients had never received $\mathrm{rGH}$ (Table 1). In the former, the median duration of the treatment was 3.0 years (range: 1-19).

All GHD males had glucocorticoid deficiency, and all of them were treated with hydrocortisone ( 25 cases)

Table 1 Clinical and biochemical features of 51 males with severe GH deficiency (GHD) and glucocorticoid deficiency enrolled in the study.

\begin{tabular}{lc}
\hline Patients & 51 \\
Age (years) & $55(23-81)$ \\
Duration of GHD (years) & $9(2-23)$ \\
rGH treatment (cases) & $21(41.2 \%)$ \\
Serum IGF1 (ng/ml) & $98(29-289)$ \\
Hypothyroidism (cases) & $39(76.4 \%)$ \\
Hypogonadism (cases) & $29(56.9 \%)$ \\
Diabetes insipidus (cases) & $6(11.7 \%)$ \\
Urinary cortisol values $(\mu \mathrm{g} / 24 \mathrm{~h})$ & $83.0(24.0-135.0)$ \\
Current cortisone dose $(\mathrm{mg} / \mathrm{day})$ & $35.0(12.5-75.0)$ \\
Cumulative cortisone dose $(\mathrm{g})$ & $91.2(13.7-321.9)$ \\
Serum $\mathrm{FT}_{4}$ values (pg/ml) & $11.2(8.9-17.6)$ \\
Serum testosterone values $(\mathrm{ng} / \mathrm{ml})$ & $4.1(1.9-14.3)$ \\
Lumbar BMD $T$-score & $-1.5(-2.7 \mathrm{to}+1.9)$ \\
Vertebral fractures & $31(60.8 \%)$
\end{tabular}

$\mathrm{rGH}$, recombinant $\mathrm{GH}$; IGF1, insulin-like growth factor $1 ; \mathrm{FT}_{4}$, free-thyroxine; $\mathrm{BMD}$, bone mineral density. or cortisone acetate (26 cases) at median daily doses of 30 and $35 \mathrm{mg}$ respectively. In each patient, the glucocorticoid dose was defined on the basis of clinical judgment (i.e. control of signs and symptoms of adrenal insufficiency) and urinary cortisol values. For uniformity of data, we expressed the glucocorticoid dose in cortisone acetate equivalent, calculated by multiplying hydrocortisone doses by 1.25. Moreover, we reported the cumulative cortisone dose calculated on the basis of duration of treatment and mean dose of cortisone or equivalent. Secondary hypothyroidism was demonstrated in 39 patients $(76.4 \%)$, hypogonadism in 29 patients $(56.9 \%)$, and diabetes insipidus in 6 patients $(11.7 \%)$. All patients were treated adequately for these pituitary deficiencies before bone analysis. Hypogonadic patients were treated with testosterone enanthate and/or propionate at doses of 200-250 mg every 2-5 weeks. The testosterone dose was adjusted on the basis of total testosterone values obtained in the last week before drug administration. The median duration of testosterone treatment was 9.5 years (range: 2-23). The patients gave informed consent to the study that was approved by local ethical committee.

BMD of the lumbar spine was measured by dualenergy X-ray absorptiometry (QDR-1000 Hologic Inc., Waltham, MA, USA), as specified previously (15). Osteopenia and osteoporosis were defined based on T-score -1.0 S.D. and -2.5 S.D. respectively, below the mean bone mass value of reference population (21).

A quantitative morphometric assessment of vertebral fracture in $\mathrm{T}_{4}-\mathrm{L}_{4}$ was performed using a dedicated morphometry software (Spine-X Analyzer ICAM Diagnostics, Milan, Italy), as described previously (15). The fractures were defined mild, moderate, and severe based on a height ratio decrease of $20-25 \%, 25-35 \%$, and more than $35 \%$ respectively.

Blood samples were collected after an overnight fast. Serum was promptly separated and stored at $-20{ }^{\circ} \mathrm{C}$ until assay. Urinary cortisol was measured using RIA (Spectria, Orion Diagnostica, Finland); in our laboratory, reference range was 36-137 $\mu \mathrm{g} / 24 \mathrm{~h}$. IGF1 was measured by Immulite 2000 (DPC, Los Angeles, CA, USA). Serum total testosterone was measured by RIA; normal range for men aged 20-49 years was $2.6-15.9 \mathrm{ng} / \mathrm{ml}$, and for men aged $>50$ years, it was $1.8-7.5 \mathrm{ng} / \mathrm{ml}$. Serum free- $\mathrm{T}_{4}\left(\mathrm{FT}_{4}\right)$ concentrations were measured by double-antibody RIA (Technogenetics, Milan, Italy); normal range was $7.0-18.0 \mathrm{pg} / \mathrm{ml}$.

\section{Statistical analysis}

All data were expressed as median and range. Unpaired data were compared using the Mann-Whitney test. Multiple comparisons were performed using KruskalWallis' test with post-hoc Bonferroni's correction. Correlation between variables was sought using Pearson's correlation. A logistic regression model was used in the statistical analysis of risk factors for the 
occurrence of vertebral fractures. Frequencies were compared using $\chi^{2}$ test with Fisher's correction, when appropriate. Statistical significance was assumed when $P$ values were $\leq 0.05$.

\section{Results}

In our patients, median BMD T-score was -1.5 S.D. (range from -2.7 to +1.9 ; Table 1 ). Fourteen patients had normal BMD, 31 (60.8\%) had osteopenia, whereas osteoporosis was demonstrated in only six patients $(11.8 \%)$. Vertebral fractures were observed in 31 patients $(60.8 \%)$ (Table 1). Fractures were single in nine patients, whereas the remaining 22 patients showed two or more fractures. Fractures were mild in 20 patients, moderate in 9, and severe in 2 patients. Sixteen patients $(51.6 \%$ of fractured patients) had one or more signs or symptoms consistent with vertebral fractures.

Univariate logistic analysis demonstrated that vertebral fractures were significantly correlated with untreated GHD, high urinary cortisol values, high current and cumulative doses of cortisone, whereas no significant correlations were demonstrated with age, $\mathrm{BMD}$, serum $\mathrm{FT}_{4}$, total testosterone, duration of hypogonadism, and age of onset of hypogonadism (Table 2). Urinary cortisol values were significantly correlated with current $(r: 0.31, P=0.03)$ and cumulative ( $r: 0.28, P=0.04)$ doses of cortisone.

Patients were stratified according to treatment of GHD, and current and cumulative cortisone doses defined as high or low when the values were higher or lower than the median value in the whole population

Table 2 Results of univariate logistic regression analysis with vertebral fractures as dependent variable, and age, bone mineral density (BMD), untreated GH deficiency (GHD), high current cortisone dose, high cumulative cortisone dose, high urinary cortisol values, serum free-thyroxine $\left(\mathrm{FT}_{4}\right)$ values, serum total testosterone values, age of onset and duration of hypogonadism as covariates. High cortisone doses and urinary cortisol values were defined as values higher than the medians in the whole population.

\begin{tabular}{llc}
\hline & \multicolumn{2}{c}{ Risk of vertebral fractures } \\
\cline { 2 - 3 } Covariates & \multicolumn{1}{c}{$\begin{array}{c}\text { Odds ratio } \\
(\mathrm{Cl} 95 \%)\end{array}$} & $P$ values \\
\hline Age & $1.01(0.97-1.05)$ & 0.53 \\
BMD $T$-score & $1.03(0.64-1.60)$ & 0.90 \\
Untreated GHD & $8.00(2.23-28.60)$ & 0.001 \\
$\begin{array}{l}\text { High current dose of } \\
\quad \text { cortisone }(>35 \text { mg/day) }\end{array}$ & $4.70(1.37-16.50)$ & 0.01 \\
$\begin{array}{l}\text { High cumulative dose of } \\
\quad \text { cortisone }(>91 \mathrm{~g})\end{array}$ & $8.40(2.21-31.70)$ & 0.002 \\
$\begin{array}{l}\text { High urinary cortisol values } \\
\quad(>83 \mu g / 24 \mathrm{~h})\end{array}$ & $5.30(1.05-18.10)$ & 0.04 \\
$\begin{array}{l}\text { Serum FT } \mathrm{F} \text { values } \\
\text { Serum total testosterone } \\
\quad \text { values }\end{array}$ & $0.91(0.73-1.14)$ & 0.44 \\
$\begin{array}{l}\text { Duration of hypogonadism } \\
\text { Age of onset of hypogonadism }\end{array}$ & $0.95(0.81-1.12)$ & 0.54 \\
\hline
\end{tabular}

(Table 1) respectively. In untreated GHD, vertebral fractures occurred more frequently in patients who had received higher cumulative (Fig. 1a) and current (Fig. 1b) cortisone doses compared with patients who had received lower doses of the drug. In untreated GHD, fractured patients showed significantly higher urinary cortisol values compared with patients without vertebral fractures $(84 \mu \mathrm{g} / 24 \mathrm{~h}$, range: $24-135$ vs $49 \mu \mathrm{g} / 24 \mathrm{~h}$, range: $30-96 ; P=0.04)$. In treated GHD patients, by contrast, the prevalence of vertebral fractures was not influenced by cumulative and current cortisone doses (Fig. 1a and b). Moreover, fractured and non-fractured patients with treated GHD showed no significant difference in urinary cortisol values (71 $\mu \mathrm{g} / 24 \mathrm{~h}$, range: $49-90$ vs $75 \mu \mathrm{g} / 24 \mathrm{~h}$, range: 38-133; $P=0.67)$.

Multivariate regression analysis demonstrated that the significant correlations between high urinary
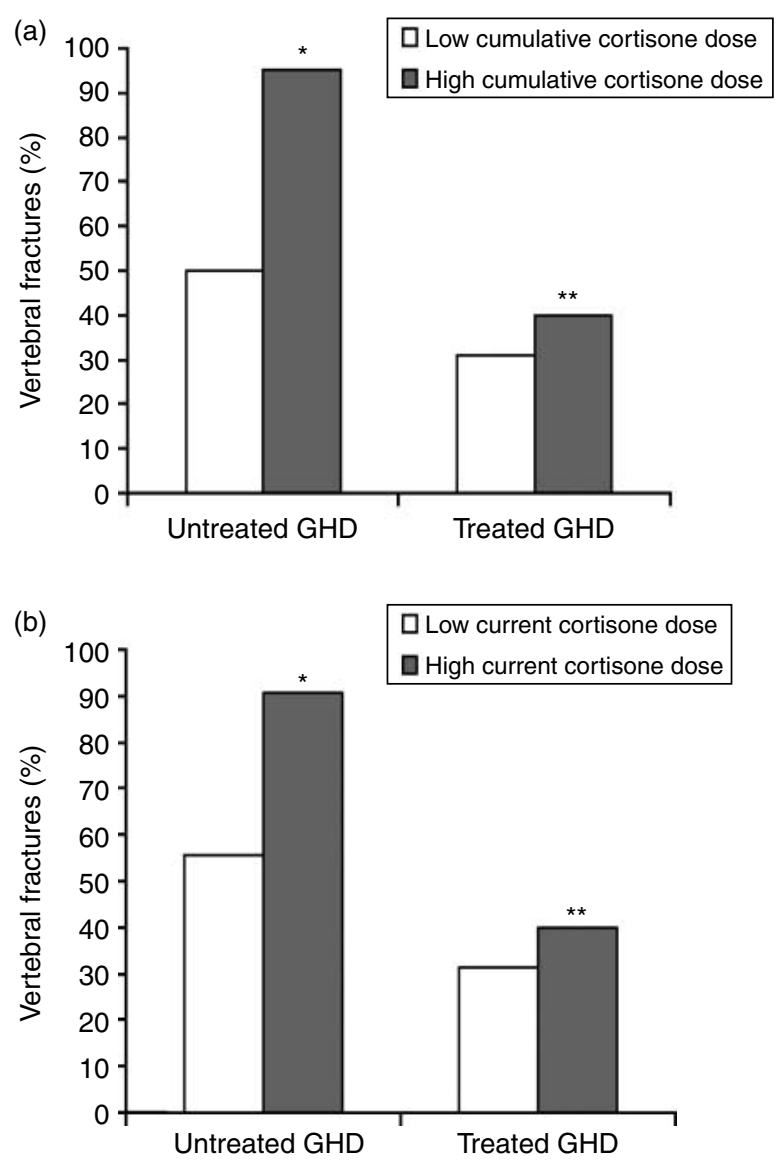

Figure 1 Prevalence of vertebral fractures in patients with $\mathrm{GH}$ deficiency (GHD) and glucocorticoid deficiency under glucocorticoid replacement stratified for treatment of GHD, and cumulative (a) and current (b) cortisone doses. Cumulative and current cortisone doses were defined as high or low when the values were higher or lower than the median value in the whole population respectively. ${ }^{\star} P<0.05$ high versus low cortisone doses; ${ }^{* \star} P<0.05$ treated versus untreated GHD. 
cortisol values, high current and cumulative doses of cortisone and vertebral fractures were lost, and untreated GHD remained the most important factor predisposing to fractures in hypopituitary patients (Table 3).

\section{Discussion}

This post hoc analysis showed that glucocorticoid replacement therapy at high doses may favor the occurrence of vertebral fractures in patients with untreated GHD. This finding was not observed in patients with treated GHD, suggesting that $\mathrm{rGH}$ replacement therapy may protect bone from the negative effects of glucocorticoid over-replacement.

Some patients taking glucocorticoid replacement therapy may be over-treated $(20,22)$. Over the last 10 years, it has been demonstrated that daily glucocorticoid doses needed to replace adrenal insufficiency are much lower than previously thought $(23,24)$. The previously recommended doses of $30 \mathrm{mg} /$ day of hydrocortisone or $37.5 \mathrm{mg} /$ day of cortisone acetate are probably too high particularly for most patients with secondary adrenal insufficiency, in whom metabolic abnormalities were demonstrated with these glucocorticoid doses (17-19). About one half of our hypopituitary patients received high replacement doses of glucocorticoids (i.e. median dose of cortisone acetate was $35 \mathrm{mg}$ ) which produced high-normal urinary cortisol values in most cases. This finding confirms that urinary cortisol may be useful to monitor replacement therapy of glucocorticoid deficiency, although in most cases a correct determination of the dose required for adequate glucocorticoid replacement is often empirical and based on clinical judgment $(20,25)$.

Glucocorticoid excess has deleterious effects on bone impairing replication, differentiation and function of osteoblasts, and inducing apoptosis of mature osteoblasts and osteocytes (2). These effects cause suppression of bone formation that is the central feature in the pathogenesis of glucocorticoid-induced osteoporosis (1). The inhibition of bone formation with osteoporosis was

Table 3 Results of multivariate logistic regression analysis using vertebral fractures as dependent variable, and untreated $\mathrm{GH}$ deficiency (GHD), high current cortisone dose, high cumulative cortisone dose and high urinary cortisol values as covariates. High cortisone doses and urinary cortisol values were defined as values higher than the medians in the whole population.

\begin{tabular}{|c|c|c|}
\hline \multirow[b]{2}{*}{ Covariates } & \multicolumn{2}{|c|}{ Risk of vertebral fractures } \\
\hline & Odds ratio ( $\mathrm{Cl} 95 \%)$ & $P$ values \\
\hline Untreated GHD & $4.71(1.20-19.01)$ & 0.03 \\
\hline $\begin{array}{l}\text { High current dose of } \\
\text { cortisone }(>35 \mathrm{mg} / \text { day })\end{array}$ & $1.01(0.18-5.80)$ & 0.99 \\
\hline $\begin{array}{l}\text { High cumulative dose of } \\
\text { cortisone }(>91 \mathrm{~g})\end{array}$ & $3.83(0.65-22.4)$ & 0.14 \\
\hline $\begin{array}{l}\text { High urinary cortisol values } \\
\qquad(>83 \mu \mathrm{g} / 24 \mathrm{~h})\end{array}$ & $1.96(0.41-9.35)$ & 0.39 \\
\hline
\end{tabular}

demonstrated even in patients receiving low doses of glucocorticoids as those used to replace adrenal insufficiency (3). The skeletal abnormalities were shown to be closely associated with glucocorticoid doses, suggesting that bone loss is an expression of glucocorticoid over-replacement. Previous studies investigated the effects of glucocorticoid replacement therapy on bone turnover and BMD (4-6). A few studies evaluated clinical fractures, suggesting that hydrocortisone use was not associated with an increase of fracture risk in the general population (7), as well as that GHD patients on glucocorticoid replacement did not have an increased risk of fracture (16). As a matter of fact, our study for the first time evaluated the effects of glucocorticoid replacement therapy on radiological vertebral fractures in patients with GHD. Vertebral fractures are often asymptomatic and largely underdiagnosed based upon clinical records. In fact, in the last decade the radiological and morphometric assessment of vertebral deformities has emerged as the method of choice for evaluating the true prevalence of fractures in population studies (26).

In a cross-sectional study, we already demonstrated that untreated GHD is associated with high risk of radiological vertebral fractures (15). In a following post-hoc analysis, we showed that this association was not influenced by gonadal status of patients (27). In the present study, the post-hoc analysis allowed to demonstrate that glucocorticoid over-replacement may further increase the prevalence of vertebral fractures in hypopituitary patients with untreated GHD. This observation is consistent with the notion that GHD and glucocorticoid excess induce similar skeletal abnormalities characterized by an inhibition of osteoblast maturation, differentiation and function $(1,8)$. Moreover, untreated GHD may be associated with an increased tissue exposure to cortisol due to increased activity of $11 \beta$-hydroxysteroid dehydrogenase type 1 (28). The association between glucocorticoid overreplacement and vertebral fractures in untreated GHD patients was independent of BMD, in agreement with previous observations reporting a poor predictive value of BMD for risk of fractures in various forms of secondary osteoporosis (29-32).

In patients with treated GHD, glucocorticoid overreplacement did not influence the occurrence of vertebral fractures, the prevalence of which was lower than that found in untreated GHD. This finding would suggest that anabolic effects of GH may protect the skeleton from the deleterious effects of subtle glucocorticoid excess. Indeed, short-term rGH treatment was shown to be effective in reverting the negative effects of glucocorticoids on bone turnover $(33,34)$. Moreover, rGH treatment may decrease the tissue exposure to glucocorticoids inhibiting the transformation of cortisone into cortisol $(35,36)$.

A limitation of our study was related to the retrospective post-hoc design which did not allow to clarify the 
timing of the effects of glucocorticoid replacement therapy on risk of fractures in GHD patients. Clinical studies performed in patients taking higher doses of glucocorticoids demonstrated that vertebral fractures occur early after glucocorticoid exposure (37). In our study, the close correlation between cumulative cortisone doses and vertebral fractures would suggest that risk of fractures may also be influenced by the duration of glucocorticoid replacement treatment. Another limitation of our study is the lack of biochemical data which may be important to support the hypothesis that GHD and glucocorticoid treatment may have additional negative effects on bone turnover in patients with hypopituitarism. Besides these drawbacks, our data may have interesting clinical implications. In fact, the significant correlation between glucocorticoid doses and urinary cortisol values may be suggestive for using this latter biochemical marker as a tool to monitor bone safety of glucocorticoid replacement therapy, despite the possible inter-individual variability $(22,25)$. The increased prevalence of vertebral fractures in patients with untreated GHD and high-normal urinary cortisol values would encourage to maintain these hormonal values in the middle or in the low-normal range to avoid glucocorticoid overtreatment even in the absence of clinically recognizable symptoms and signs of hypercortisolism. Finally, based on the lack of correlation between BMD and fractures, it appears reasonable to suggest to monitor glucocorticoid treatment by the morphometric approach in order to identify early and easily patients with unsuspected vertebral fractures. Epidemiological studies have pointed out the necessity to identify early vertebral fractures, since the presence of a single fracture even if mild and without clinical symptoms predisposes to have other more severe fractures with consequent greater clinical impact (38-40).

In conclusion, our data suggest that in untreated GHD even subtle glucocorticoid overtreatment should be avoided due to synergistic deleterious skeletal effects. Conversely, GH replacement treatment appears to minimize negative effects of glucocorticoid excess on bone health.

\section{Declaration of interest}

The authors declare that there is no conflict of interest that could be perceived as prejudicing the impartiality of the research reported.

\section{Funding}

This work was supported by MIUR and Centro di Ricerca sull'Osteoporosi-University of Brescia/EULO (A Giustina).

\section{References}

1 Mazziotti G, Angeli A, Bilezikian JP, Canalis E \& Giustina A. Glucocorticoid-induced osteoporosis: an update. Trends in Endocrinology and Metabolism 200617 144-149.
2 Canalis E \& Giustina A. Glucocorticoid-induced osteoporosis: summary of a workshop. Journal of Clinical Endocrinology and Metabolism $2001 \mathbf{8 6} 5681-5685$.

3 Wichers M, Springer W, Bidlingmaier F \& Klingmuller D. The influence of hydrocortisone substitution on the quality of life and parameters of bone metabolism in patients with secondary hypocortisolism. Clinical Endocrinology 199950 759-765.

4 Zelissen PM, Croughs RJ, van Rijk PP \& Raymakers JA. Effect of glucocorticoid replacement therapy on bone mineral density in patients with Addison disease. Annals of Internal Medicine 1994 120 207-210.

5 Jódar E, Valdepeñas MP, Martinez G, Jara A \& Hawkins F. Long-term follow-up of bone mineral density in Addison's disease. Clinical Endocrinology $2003 \mathbf{5 8} 617-620$.

6 Braatvedt GD, Joyce M, Evans M, Clearwater J \& Reid IR. Bone mineral density in patients with treated Addison's disease. Osteoporosis International 199910 435-440.

7 Vestergaard P, Rejnmark L \& Mosekilde L. Fracture risk associated with different types of oral corticosteroids and effect of termination of corticosteroids on the risk of fractures. Calcified Tissue International $2008 \mathbf{8 2} 249-257$.

8 Giustina A, Mazziotti G \& Canalis E. Growth hormone, insulin-like growth factors, and the skeleton. Endocrine Reviews $2008 \mathbf{2 9}$ 535-559.

9 Canalis E, Giustina A \& Bilezikian JP. Mechanisms of anabolic therapies for osteoporosis. New England Journal of Medicine 2007 357 905-916.

10 Digirolamo DJ, Mukherjee A, Fulzele K, Gan Y, Cao X, Frank SJ \& Clemens TL. Mode of growth hormone action in osteoblasts. Journal of Biological Chemistry 2007282 31666-31674.

11 Doga M, Bonadonna S, Gola M, Mazziotti G, Nuzzo M \& Giustina A. GH deficiency in the adult and bone. Journal of Endocrinological Investigation $2005 \mathbf{2 8}$ (Suppl 8) 18-23.

12 Rosen T, Wilhelmsen L, Landin-Wilhelmsen K, Lappas G \& Bengtsson BA. Increased fracture frequency in adult patients with hypopituitarism and GH deficiency. European Journal of Endocrinology 1997137 240-245.

13 Wuster C, Abs R, Bengtsson BA, Bennmarker H, Feldt-Rasmussen U, Hernberg-Stahl E, Monson JP, Westberg B, Wilton P \& KIMS Study Group and the KIMS International Board Pharmacia \& Upjohn International Metabolic Database. The influence of growth hormone deficiency, growth hormone replacement therapy, and other aspects of hypopituitarism on fracture rate and bone mineral density. Journal of Bone and Mineral Research 200116 398-405.

14 Bouillon R, Koledova E, Bezlepkina O, Nijs J, Shavrikhova E, Nagaeva E, Chikulaeva O, Peterkova V, Dedov I, Bakulin A, Oganov V \& Attanasio AF. Bone status and fracture prevalence in Russian adults with childhood-onset growth hormone deficiency. Journal of Clinical Endocrinology and Metabolism $2004 \mathbf{8 9}$ 4993-4998.

15 Mazziotti G, Bianchi A, Bonadonna S, Nuzzo M, Cimino V, Fusco A, De Marinis L \& Giustina A. Increased prevalence of radiological spinal deformities in adult patients with GH deficiency: influence of GH replacement therapy. Journal of Bone and Mineral Research $200621520-528$.

16 Vestergaard P, Jørgensen JO, Hagen C, Hoeck HC, Laurberg P, Rejnmark L, Brixen K, Weeke J, Andersen M, Conceicao FL, Nielsen TL \& Mosekilde L. Fracture risk is increased in patients with GH deficiency or untreated prolactinomas - a case-control study. Clinical Endocrinology 200256 159-167.

17 Danilowicz K, Bruno OD, Manavela M, Gomez RM \& Barkan A. Correction of cortisol overreplacement ameliorates morbidities in patients with hypopituitarism: a pilot study. Pituitary 200811 279-285.

18 Filipsson H, Monson JP, Koltowska-Häggström M, Mattsson A \& Johannsson G. The impact of glucocorticoid replacement regimens on metabolic outcome and comorbidity in hypopituitary patients. Journal of Clinical Endocrinology and Metabolism 200691 3954-3961. 
19 al-Shoumer KA, Beshyah SA, Niththyananthan R \& Johnston DG. Effect of glucocorticoid replacement therapy on glucose tolerance and intermediary metabolites in hypopituitary adults. Clinical Endocrinology 199542 85-90.

20 Filipsson H \& Johannsson G. GH replacement in adults: interactions with other pituitary hormone deficiencies and replacement therapies. European Journal of Endocrinology 2009 161 (Suppl 1) S85-S95.

21 Kanis JA, Delmas P, Burckhardt P, Cooper C \& Torgerson D. Guidelines for diagnosis and management of osteoporosis. The European Foundation for Osteoporosis and Bone Disease. Osteoporosis International 19977 390-406.

22 Debono M, Price JN \& Ross RJ. Novel strategies for hydrocortisone replacement. Best Practice \& Research. Clinical Endocrinology \& Metabolism 200923 221-232.

23 Esteban NV, Loughlin T, Yergey AL, Zawadzki JK, Booth JD, Winterer JC \& Loriaux DL. Daily cortisol production rate in man determined by stable isotope dilution/mass spectrometry. Journal of Clinical Endocrinology and Metabolism 199172 39-45.

24 Kraan GP, Dullaart RP, Pratt JJ, Wolthers BG, Drayer NM \& De Bruin R. The daily cortisol production reinvestigated in healthy men. The serum and urinary cortisol production rates are not significantly different. Journal of Clinical Endocrinology and Metabolism 199883 1247-1252.

25 Trainer PJ, McHardy KC, Harvey RD \& Reid IW. Urinary free cortisol in the assessment of hydrocortisone replacement therapy. Hormone and Metabolic Research 199325 117-120.

26 Majumdar SR, Kim N, Colman I, Chahal AM, Raymond G, Jen H, Siminoski KG, Hanley DA \& Rowe BH. Incidental vertebral fractures discovered with chest radiography in the emergency department: prevalence, recognition, and osteoporosis management in a cohort of elderly patients. Archives of Internal Medicine 2005165 905-909.

27 Mazziotti G, Bianchi A, Cimino V, Bonadonna S, Martini P, Fusco A, De Marinis L \& Giustina A. Effect of gonadal status on bone mineral density and radiological spinal deformities in adult patients with growth hormone deficiency. Pituitary 200811 55-61.

28 Wake DJ, Rask E, Livingstone DE, Soderberg S, Olsson T \& Walker BR. Local and systemic impact of transcriptional up-regulation of 11beta-hydroxysteroid dehydrogenase type 1 in adipose tissue in human obesity. Journal of Clinical Endocrinology and Metabolism $2003 \mathbf{8 8} 3983-3988$.

29 Canalis E, Mazziotti G, Giustina A \& Bilezikian JP. Glucocorticoidinduced osteoporosis: pathophysiology and therapy. Osteoporosis International 200718 1319-1328.

30 Bonadonna S, Mazziotti G, Nuzzo M, Bianchi A, Fusco A, De Marinis L \& Giustina A. Increased prevalence of radiological spinal deformities in active acromegaly: a cross-sectional study in postmenopausal women. Journal of Bone and Mineral Research 200520 1837-1844.

31 Vestergaard P. Discrepancies in bone mineral density and fracture risk in patients with type 1 and type 2 diabetes - a meta-analysis. Osteoporosis International $2007 \mathbf{1 8} 427-444$.

32 Mazziotti G, Bianchi A, Bonadonna S, Cimino V, Patelli I, Fusco A, Pontecorvi A, De Marinis L \& Giustina A. Prevalence of vertebral fractures in men with acromegaly. Journal of Clinical Endocrinology and Metabolism 200893 4649-4655.
33 Giustina A, Bussi AR, Jacobello C \& Wehrenberg WB. Effects of recombinant human growth hormone $(\mathrm{GH})$ on bone and intermediary metabolism in patients receiving chronic glucocorticoid treatment with suppressed endogenous GH response to GH-releasing hormone. Journal of Clinical Endocrinology and Metabolism $1995 \mathbf{8 0} 122-129$.

34 Bechtold S, Ripperger P, Bonfig W, Dalla Pozza R, Häfner R \& Schwarz H. Growth hormone changes bone geometry and body composition in patients with juvenile idiopathic arthritis requiring glucocorticoid treatment: a controlled study using peripheral quantitative computed tomography. Journal of Clinical Endocrinology and Metabolism 200590 3168-3173.

35 Swords FM, Carroll PV, Kisalu J, Wood PJ, Taylor NF \& Monson JP. The effects of growth hormone deficiency and replacement on glucocorticoid exposure in hypopituitary patients on cortisone acetate and hydrocortisone replacement. Clinical Endocrinology $200359613-620$.

36 Giavoli C, Libe R, Corbetta S, Ferrante E, Lania A, Arosio M, Spada A \& Beck-Peccoz P. Effect of recombinant human growth hormone $(\mathrm{GH})$ replacement on the hypothalamic-pituitaryadrenal axis in adult GH-deficient patients. Journal of Clinical Endocrinology and Metabolism 200489 5397-5401.

37 van Staa TP, Leufkens HG, Abenhaim L, Zhang B \& Cooper C. Use of oral corticosteroids and risk of fractures. Journal of Bone and Mineral Research 200015 993-1000.

38 Reeve J, Lunt M, Felsenberg D, Silman AJ, Scheidt-Nave C, Poor G, Gennari C, Weber K, Lorenc R, Masaryk P, Cannata JB, Dequeker J, Reid DM, Pols HA, Benevolenskaya LI, Stepan JJ, Miazgowski T, Bhalla A, Bruges Armas J, Eastell R, Lopes-Vaz A, Lyritis G, Jajic I, Woolf AD, Banzer D, Reisinger W, Todd CJ, Felsch B, Havelka S, Hoszowski K, Janott J, Johnell O, Raspe HH, Yershova OB, Kanis JA, Armbrecht G, Finn JD, Gowin W, O'Neill TW \& European Prospective Osteoporosis Study Group. Determinants of the size of incident vertebral deformities in European men and women in the sixth to ninth decades of age: the European prospective osteoporosis study. Journal of Bone and Mineral Research 200318 1664-1673.

39 Silverman SL, Minshall ME, Shen W, Harper KD, Xie S \& HealthRelated Quality of Life Subgroup of the Multiple Outcomes of Raloxifene Evaluation Study. The relationship of health-related quality of life to prevalent and incident vertebral fractures in postmenopausal women with osteoporosis: results from the multiple outcomes of raloxifene evaluation study. Arthritis and Rheumatism 200144 2611-2619.

40 O'Neill TW, Cockerill W, Matthis C, Raspe HH, Lunt M, Cooper C, Banzer D, Cannata JB, Naves M, Felsch B, Felsenberg D, Janott J, Johnell O, Kanis JA, Kragl G, Lopes Vaz A, Lyritis G, Masaryk P, Poor G, Reid DM, Reisinger W, Scheidt-Nave C, Stepan JJ, Todd CJ, Woolf AD, Reeve J \& Silman AJ. Back pain, disability, and radiographic vertebral fracture in European women: a prospective study. Osteoporosis International 200415 760-765.

Received 25 March 2010

Accepted 8 April 2010 